\title{
Edward Eyre Hunt 1922-1991
}

\author{
Stanley M. Garn \\ Center for Human Growth and Development \\ $300 \mathrm{~N}$. Ingalls, 10th Level \\ University of Michigan \\ Ann Arbor, Michigan 48109-0406
}

Edward Eyre Hunt, one of the co-founders of the Dental Anthropology Association, died six months short of his 70th year. He led two separate careers of approximately equal length. The first was at the Forsyth Dental Infirmary in Boston, with instructional and then assistant professorial rank at Harvard. During that time he was the recipient of two successive Career Development Awards. The second, after a brief period of teaching at Hunter and C.U.N.Y., was at the Pennsylvania State University, until his retirement in 1985. At the Forsyth he had influence on a long series of dental interns and initiated studies on tooth formation timing that included data from three different growth studies. At Penn State he extended his teaching to include epidemiology and health education and gained a singular reputation as an inspired teacher, ever ready to help graduate students plan and execute their research.

Ed Hunt frequented libraries, deeply delving into the literature and retaining what he read, a singular advantage in the pre-Medlar years. He could, therefore, recover from his memory bank a rather complete bibliography on any selected subject, saving students hours of searching in their own, and adding depth to his subject-reviews and position papers. That ability, plus his broad-knowledge of mathematical statistics, is fully evident in his now classic 1966 paper on developmental genetics. No wonder Carleton Coon was delighted to have Ed Hunt as collaborator on numerous books.

During World War II, Ed served as a psychological statistician with the Flying Safety Branch, Army Air Force. In the course of his graduate career at Harvard, which began in 1946, he was involved in studies on depopulation in Yap adding demography to his expertise. Though later afflicted with a form of lymphoma, he responded to chemotherapy.

In $1952 \mathrm{Ed}$ married an Australian dentist (Vilma Maxine Rose Dalton-Webb), and in 1956 held a Fulbright Lectureship at the University of Melbourne. At several points in time Ed and Vilma contemplated relocation in Australia.

Ed Hunt devoted an extraordinary amount of time helping others both in his academic positions and in his expansive Victorian home in Magnolia, Massachusetts, where he maintained a kind of residential salon for years. When he retired to Magnolia, he did not retire, continuing to work on the history of Science, and on the history of physical anthropology in the U.S.A. up to the time of his death. 